\title{
Alkali-resistant glass fiber reinforced high strength concrete in simulated aggressive environment
}

\author{
W.H. Kwan $₫$, C.B. Cheah, M. Ramli, K.Y. Chang.
}

a. Department of Construction Management, Universiti Tunku Abdul Rahman, (Malaysia)

b. School of Housing, Building and Planning, Universiti Sains Malaysia, (Malaysia) \kwanwh@utar.edu.my

\author{
Received 6 December 2016 \\ Accepted 23 May 2017 \\ Available on line 13 February 2018
}

\begin{abstract}
The durability of the alkali-resistant (AR) glass fiber reinforced concrete (GFRC) in three simulated aggresive environments, namely tropical climate, cyclic air and seawater and seawater immersion was investigated. Durability examinations include chloride diffusion, gas permeability, X-ray diffraction (XRD) and scanning electron microscopy examination (SEM). The fiber content is in the range of $0.6 \%$ to $2.4 \%$. Results reveal that the specimen containing highest AR glass fiber content suffered severe strength loss in seawater environment and relatively milder strength loss under cyclic conditions. The permeability property was found to be more inferior with the increase in the fiber content of the concrete. This suggests that the AR glass fiber is not suitable for use as the fiber reinforcement in concrete is exposed to seawater. However, in both the tropical climate and cyclic wetting and drying, the incorporation of AR glass fiber prevents a drastic increase in permeability.
\end{abstract}

KEYWORDS: Fibre reinforcement; Glass; Sulphate attack; X-ray Diffraction (XRD); Scanning Electron Microscopy (SEM).

Citation/Citar como: Kwan, W.H.; Cheah, C.B.; Ramli, M.; Chang, K.Y. (2018) Alkali-resistant glass fiber reinforced high strength concrete in simulated aggressive environment. Mater. Construcc. 68 [329], e147. https://doi.org/10.3989/ mc.2018.13216

Resumen: Hormigón de altas resistencia reforzado con fibras de vidrio resistentes a alcalis en ambientes agresivos simulados. Este trabajo se centra en el estudio de la durabilidad de hormigón reforzado con fibra de vidrio resistente a álcalis (CRFVRA) en tres ambientes agresivos simulados como son, condiciones de clima tropical, ciclos de aire y agua de mar e inmersión marina. Los tests de durabilidad incluyeron la difusión de cloruros, permeabilidad de gas, difracción de rayos X (XRD) y evaluacion por microscopía electrónica de barrido (SEM). Los contenidos de fibra evaluados estuvieron en el rango desde $0.6 \%$ hasta $2.4 \%$.

Los resultados revelan que la muestra que contiene el mayor porcentaje de fibra sufre una severa pérdida de resistencia en condiciones de agua de mar, y una menor disminución de resistencia bajo condiciones cíclicas. Su permeabilidad disminuyó al incrementar el contenido de fibras en el hormigón. Lo anterior sugiere que el refuerzo con fibra resistente a alcalinos no es adecuado para su uso en hormigón en ambiente de agua de mar. Sin embargo, bajo condiciones de clima tropical, y en ciclos humedad/secado, la incorporación de dichas fibras previene un incremento drástico de la permeabilidad.

Palabras clave: Refuerzo de fibra; Vidrio; Ataque por sulfatos; Difracción de rayos X (XRD); Microscopía electrónica de barrido (SEM)

ORCID ID: W.H. Kwan (http://orcid.org/0000-0003-1079-613X); C.B. Cheah (http://orcid.org/0000-0003-2261-2991); M. Ramli (http://orcid.org/0000-0003-3359-9411); K.Y. Chang (http://orcid.org/0000-0003-3895-5278)

Copyright: (C) 2018 CSIC. This is an open-access article distributed under the terms of the Creative Commons Attribution 4.0 International (CC BY 4.0) License. 


\section{INTRODUCTION}

Aggressive environment attacks such as sulphate attacks, chloride ingress, dimensional instability, salt crystallization and etc. causes deleterious effects to the concrete. Those deleterious effects mainly deal with cracks formation, either caused by the formation of expansive products or rapid expansion and shrinkage due to the drying-wetting cycles. Chloride diffusion triggers the corrosion of steel reinforcement and initiates salt crystal formation within the concrete. Sulphate attack results in the formation of ettringite and gypsum, which are both expansive in nature. These products exert internal stress on the hardened cement paste of concrete and resulting in crack formation (1-4). Wetting-drying cycles at the splash zones violate the dimensional stability of the concrete matrix. The same mechanism occurs in tropical climate exposure as intensive solar radiation that heats up the cementitious matrix followed by rain water spraying, or vice-versa, causes a drastic change in the temperature.

As concrete is a brittle material, the shrinkage and expansion stresses by the cyclic wetting and drying induce the micro cracks within the concrete structure. Under such circumstances, it leads to the formation of stress concentration zones in a concrete microstructure even without being subjected to external load or environmental effects. When the external load, differential shrinkage, and environmental factors come into the picture, the cracks would be increased and further propagated resulting in crack localization and failure of concrete (5). Although high performance concrete which offers low permeability was adopted as the best approach to address the durability issues, it helps to delay the penetration of the external substances for a period of time only. However, once surface crack is initiated by the weathering effect or diffusion of sulphate ions, the original purpose of using low permeability concrete will be jeopardized (6).

In order to mitigate this problem, chopped strand AR glass fiber is proposed in this study to provide a localized reinforcing effect within the cementitious matrix in order to control the crack formation and subsequent propagations due to the exposure to the aggressive environment. These fine fibers are densely scattered in the binder matrix in order to provide localized restrains in random directions to control micro cracks openings and propagation of cracks (7-10). Disodium oxide $\left(\mathrm{Na}_{2} \mathrm{O}\right)$ and dipotassium oxide $\left(\mathrm{K}_{2} \mathrm{O}\right)$ are low in glass fiber and therefore it enhances the corrosion resistance to water and higher surface resistivity. The molecular structure of glass fiber consists of three dimensional, long network of $\mathrm{Si}, \mathrm{O}_{2}$ and other randomly arranged atoms. Thus, glass fibers are amorphous (non-crystalline) and isotropic, which means that their properties remain the same in all directions
$(11,12)$. Nevertheless, normal glass fiber is not chemically stable in concrete due to the high alkalinity. Alkaline resistance fiber is the modified version which was developed by Cem-Fil ${ }^{\circledR}$. The impregnation of glass fibers by zirconium $\left(\mathrm{ZrO}_{2}\right)$ acts as a component in the molecular structure of glass fiber which improves the resistance against alkaline corrosion. The minimum percentage of the zirconia content is $16 \%(13-15)$.

Incorporating discontinuous fibers in the concrete matrix provides several advantages such as enhanced matrix integrity, ductility and shear strength, greater damage tolerance and energy absorption capacity under impact and cyclic loading, better dimensional stability (reduced shrinkages and expansions) (16-22). In terms of greater dimensional stability, the use of glass fibers as discrete reinforcements in concrete has been proven to enhance the crack resistance and durability of concrete. Barluenga \& Hernández-Olivares (23) found that AR glass fibers could provide local reinforcement effects at early ages (less than 24 hours) which substantially reduce the total cracked area and the maximum crack length of a slab panel. It was also observed that the fiber content should be maintained low $\left(600 \mathrm{~g} / \mathrm{m}^{3}\right)$ so that the cracks will mainly be perpendicular to the fiber orientations in order to maximize the reinforcing effect of the fiber. Besides that, Messan, Ienny, \& Nectoux (24) reached a similar condition. Both the overall shrinkage and heterogeneity of the surface shrinkage of the free and restrained mortar specimens at early ages are largely reduced by the use of glass fiber as discrete reinforcement.

With respect to the durability of the AR glass fibers in concrete matrix, although it is guaranteed by the presence of zirconium; the reduction in strength over a long period of exposure in moist mediums has been reported in some literature (25, 26). The presence of portlandite $\left[\mathrm{Ca}(\mathrm{OH})_{2}\right]$ in the pore water of cementitious matrix creates a highly alkaline condition in the matrix. This condition triggers the degradation process of the fibers as the hydroxyl ions $\left(\mathrm{OH}^{-}\right)$from portlandite attack the Si-O-Si structural network of the glass fiber. The AR glass fiber which is coated with $\mathrm{ZrO}_{2}$ is less susceptible to the attack because $\mathrm{Zr}-\mathrm{O}$ bonds are less reactive to $\mathrm{OH}^{-}$ions. Hence, the alkalinity of pore water (i.e. the availability of the $\mathrm{OH}^{-}$ions) governs the rate of degradation of glass fiber (26, 27). Nourredine (25) reported that the addition of silica fume slows down the degradation process. This is because the pozzolanic reactions between the silica fume and portlandite produced from the primary hydration of cement have further reduced the amount of portlandite. However, the viability of incorporating AR glass fibers in high strength concrete that are exposed to the seawater exposure environment in the long-term has yet to be explored. 


\section{EXPERIMENTAL PROGRAMME}

The constituent materials of the high strength concrete used in the study are Portland cement, condensed silica fume, washed river sand (specific gravity 2.63), coarse aggregate of granitic origin (specific gravity 2.65), sulphonated superplasticizer, tap water and AR glass fibers. The chemical compositions of Portland cement are provided by the supplier (Tasek Corporation Sdn. Bhd). The glass fiber used in the study is in bundle form, consisting of \pm 200 filaments and loosely bound together. The diameters ranged between $12 \mu \mathrm{m}$ and $20 \mu \mathrm{m}$ for each filament and the specifications are presented in Table 1. Five different mix designs were examined in the study: one control specimen (without fiber) and four other mixes containing $0.6 \%, 1.2 \%$, $1.8 \%$ and $2.4 \%$ of AR glass fibers. The percentage of fibers was calculated based on the total binder volume. The plain specimen was denoted as CTRL, whereas the others were denoted according to the fiber content. For example, the $0.6 \mathrm{GF}$ refers to the specimen containing $0.6 \%$ of glass fiber. The binder content was fixed at $495 \mathrm{~kg} / \mathrm{m}^{3}$. Silica fume occupied $12 \%$ of the total binder content. The water to binder ratio was fixed at 0.35 and the fine to coarse aggregate ratio was 2:3. Sulphonated-based superplastizer was added at a constant dosage of $2 \%$ by weight of binder to achieve a workable mix with the slump class of $\mathrm{S} 1(10-40 \mathrm{~mm})$ as defined in British Standard BS EN 206.

All specimens were water cured for 28 days by being exposed to three different simulated aggressive environments for periods of $3,6,12$, and 18 months. The early-age performance of specimens under water curing was regarded as the reference for the pre-aggressive environment exposures (28). The simulated aggressive environments are tropical air (A-series), cyclic wetting and drying in tropical air (N-series) and continuous immersion in seawater (W-series). The A-series concrete specimens were cured in air with recorded temperatures ranging between $23-32{ }^{\circ} \mathrm{C}$ and relative humidity of between $65-79 \%$. The specimens were subjected to sun radiations and rains. $\mathrm{N}$-series was cured under 14-day cycle of wetting and drying (4 days in seawater and 10 days in the air environment like the A-series). W-series concrete specimens were subjected to continuous immersion in seawater, at the temperature of $25 \pm 2{ }^{\circ} \mathrm{C}$.

The parameters of the study include compressive strength, intrinsic permeability, chloride penetration, X-ray diffraction (XRD), scanning electron microscopy (SEM) examination and energy dispersive X-ray spectrography (EDX). X-Ray diffraction analysis was performed on samples subjected to the immersion in seawater to identify the minerals which are related to sulphate attack on concrete namely gypsum and sepiolite. Compressive strength was determined from the average of five concrete cubes with the dimension of $100 \times 100 \times 100 \mathrm{~mm}$, and the testing procedures were done in accordance with BS EN 12390-3 (29). The testing procedure developed by Cabrera \& Lynsdale (30) was adopted in determining the intrinsic permeability. Six cylindrical samples with the dimension of $45 \mathrm{~mm} \varnothing \times 40$ $\mathrm{mm}$ which cored from three prisms were used. The cored samples were placed into a ventilated oven until it achieved mass equilibrium, usually after 72 \pm 2 hours. Next, the samples were cooled to room temperature in a desiccator and tested with Leed Cell Apparatus. The intrinsic permeability was calculated as Equation [1] below:

$$
K=\frac{\left(2 P_{2} V L \times 1.76 \times 10^{-16}\right)}{A\left(P 1^{2}-P 2^{2}\right)}
$$

The chloride diffusion study was performed to assess the chloride performance of the GFRC under the exposure to chloride rich exposure condition. The titration method was adopted to examine the chloride penetration which was in accordance with BS 1881 - 124 (31). Six cylinders were extracted from three separate prisms and sliced according to the respective depth levels using a diamond cutter. The sliced samples from the same depth level were

TABLE 1. Specification of the AR glass fiber

\begin{tabular}{lccc}
\hline Description & Unit & Standard & Test Value \\
\hline Diameter & $\mu \mathrm{m}$ & $15.0 \pm 2.3$ & 15.7 \\
Length & $\mathrm{mm}$ & $24 \pm 1.5$ & 24.4 \\
Moisture content & $\%$ & $\leq 0.2$ & 0.18 \\
Combustible matter content & $\%$ & $1.9 \pm 0.3$ & 1.83 \\
Elastic modulus & $\mathrm{GPa}$ & 71.7 to 80.0 & 72 \\
Specific gravity & - & 2.6 to 2.8 & 2.7 \\
$\mathrm{ZrO}_{2}$ & $\%$ & $16.8 \pm 0.5 / 0.3$ & 16.57 \\
$\mathrm{TiO}_{2}$ & $\%$ & $5.5 \pm 0.5$ & 5.45 \\
\hline
\end{tabular}


then ground into fine powder to achieve uniformity. Subsequently, $5 \pm 0.005 \mathrm{~g}$ of fine powder was diluted with $50 \mathrm{ml}$ of deionized water and followed by $10 \mathrm{~mL}$ of nitric acid. Next, another $50 \mathrm{~mL}$ of hot water was added into the solution and boiled for $4-5$ minutes. The solution was kept warm for $10-15$ minutes and allowed to cool to room temperature. Next, it was filtered with ashless filter paper and excessive $0.1 \mathrm{M}$ silver nitrate was added into the solution, followed by 3,5,5-trimethylhexanol and iron (III) indicator solution. The last step was to titrate with thiocyanate standard solution until the first permanent red color was noticed. The chloride content, J (percentage to mass of cement) was calculated by using Equation [2] as written below:

$$
J=\left\{V_{5}-\frac{V_{6} m}{0.1}\right\} \frac{0.3545}{M_{c}} \times \frac{100}{C_{1}}
$$

A mineralogical study was performed by the XRD analysis on the concrete core subjected to the seawater immersion to confirm the seawater attacks and the presence of portlandite. Samples were extracted from the outer layer of the CTRL and 2.4GF prisms with the longest exposure (18 months) to the aggressive environments. Samples were ground into powder form and then irradiated by an X-ray beam at various scattering angles of 2 Theta scale between $5^{\circ}-40^{\circ}$. Meanwhile, the SEM examination and EDX analysis were performed to observe the microstructure at the fiber/matrix interfacial transition zone and the condition of fiber after being exposed to the aggressive environments. Thus, samples were extracted using the diamond core cutter and only those which contain fiber at the surface were selected. The selected samples were then coated with pure gold in a vacuum chamber. The scanning electron microscope used was GEMINI SUPRA 50 VP. The primary electron beam was accelerated with the energy of $15 \mathrm{kV}$ and the electron bombardment was used to generate the Energy Dispersive X-ray spectrography (EDX).

\section{RESULTS AND DISCUSSION}

\subsection{Compressive Strength}

The compressive strength of the CTRL and GFRCs in different simulated environments is presented in Figure 1 to Figure 3. Based on the results in Figure 1, the compressive strength of GFRCs was decreased after being exposed to tropical air environment (A-series) for 18 months. Prior to exposure, the compressive strength of $2.4 \mathrm{GF}$ was 75.01 $\mathrm{MPa}$ which is the highest and 5.0\% higher than the CTRL. With reference to the test result, it could be observed that upon the addition of the AR fiber at low volume fraction, the increase in the paste-fiber interfacial transition zone (ITZ) resulted in a weaker matrix which outweighed the crack bridging effect of the fiber which contributed towards a reduced compressive strength. As the volume fraction of the fiber increases, the presence of higher amount of fiber enables a better crack bridging effect which in turn outweighs the deleterious effect due to the increased ITZ within the concrete matrix. This is evident with the clear trend of the increasing compressive strength with increased fiber volume fraction at the stage prior to exposure as shown in Figure 1 -Figure 3. After the A-series exposure for 18 months, the strength of $2.4 \mathrm{GF}$ recorded at $70.36 \mathrm{MPa}$ which is $8.9 \%$ lower than the CTRL $(77.18 \mathrm{MPa})$. The strength development trends of the GFRCs in A-series exposure are similar where the most significant dropping point is after 12 months' exposure.

The drop in the compressive strength of the GFRCs after long term exposure is caused by premature fracture of fiber filaments. Since the glass fibers used in this study are in bundle form and consist of \pm 200 filaments which are loosely bonded together, the binder matrix did not penetrate into the bundles which leave some empty space between filaments, and strand/matrix interfaces. These empty spaces were densified by the precipitation of portlandite from the hydration process $(1,32)$. Although the densification process increases the bonding strength between the strand/matrix interfaces and filaments within the bundle, it has two detrimental effects to the fibers. Firstly, as the interface hardens, the cracks in the matrix would directly penetrate into the fibers, instead of diverting around the interface. This would create flaws and weaken the tiny filaments (33). Secondly, when the interface between filaments becomes denser, the radius of the curvature that can support the fracture becomes bigger, i.e. the filament can bend lesser. This would induce higher flexural stress when the fiber is being subjected to the bending mechanism, and this may lead to premature fracture in tiny filaments.

Hence, the fractured filaments lose their capability to serve as localized reinforcements to control the development of micro cracks within the

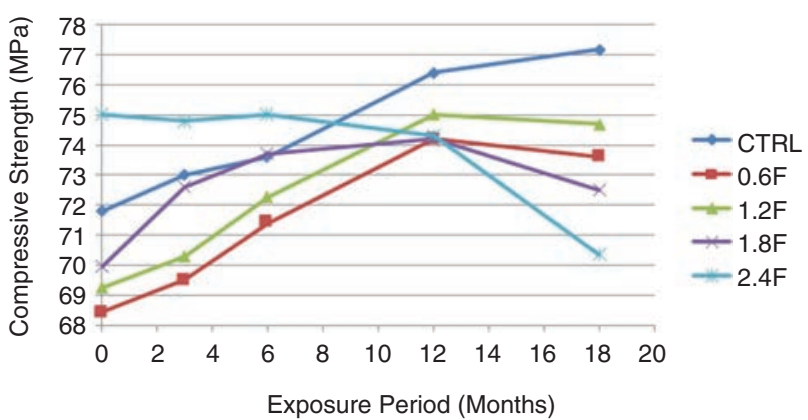

Figure 1. Compressive strength A-series specimens versus the exposure period. 


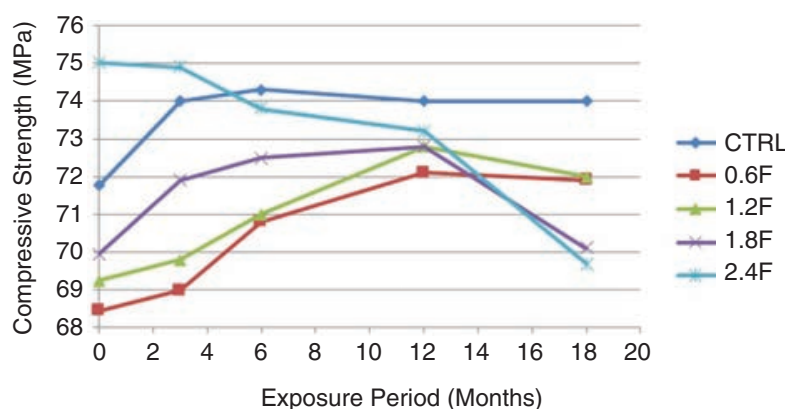

FIGURE 2. Compressive strength N-series series versus the exposure period.

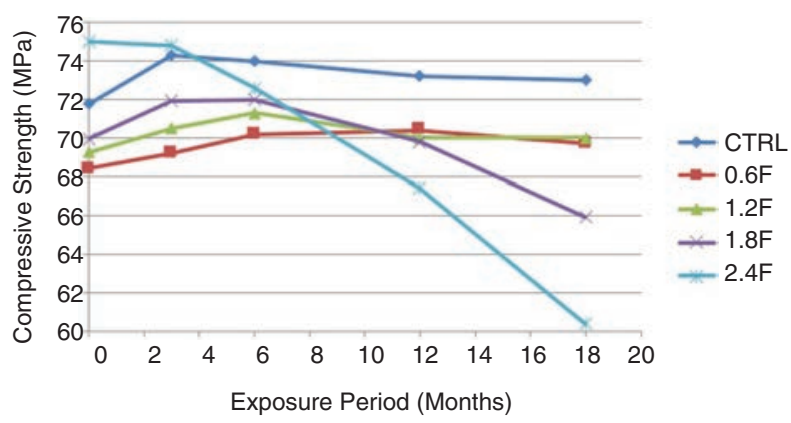

Figure 3. Compressive strength W-series specimens versus the exposure period.

cementitious matrix. This scenario was observed in the microstructure study as shown in Figure 10. Moreover, the weak fiber/matrix interface zone will serve as an initial point of crack when the cementitious composite is subjected to compressive stress. These will subsequently lead to the reduction in the compressive strength of the GFRCs. When the fiber is incorporated at high dosage $(\geq 1.8 \%)$, the deleterious effects such as moisture attacks, premature fracture, increased permeability and porosity etc. are magnified.

The results shown in Figure 2 reveal that it was also detrimental to have high fiber content in the cyclic exposure condition. Cyclic exposure condition is more intense in terms of the volume change due to the wetting-drying cycles which happen every 14 days compared with A-series. During the wetting period, the specimens also suffered from seawater attacks. The $2.4 \mathrm{GF}$ specimens started losing strength at earlier exposure period ( 6 months) compared with the A-series, and the compressive strength is lower than that of the CTRL by $5.8 \%$, at $69.69 \mathrm{MPa}$. It was caused by the higher dosage of fibers incorporated as it led to permeability and porosity; and other deleterious effects which allow for the chemical corrosion of glass fibers. Meanwhile, the other GFRCs started dropping strength significantly after 12 months' exposure caused by the premature fracture of fiber filaments.

The results in Figure 3 show that the most significant reduction in the compressive strength on prolonged exposure duration can be observed for GFRC with high fiber content $(\geq 1.8 \%)$ subjected to prolonged immersion in seawater. The $2.4 \mathrm{GF}$ suffered the largest strength loss, which is $17.2 \%$ lower than that of the CTRL. The strength dropped continuously, from $75.01 \mathrm{MPa}$ to $60.39 \mathrm{MPa}$, i.e. about $19.5 \%$ after prolonged immersion in seawater for 18 months. The rapid reduction in strength was observed to occur after 3 months. The substantial loss of strengths is highly possible due to the chemical corrosion of the glass fibers and porous microstructure surrounding the fiber filaments. This is evident in the SEM examinations which showed that the fiber filament has already been damaged. Literature recommends that lowering portlandite content and the glass fibers coated with zirconium oxide could have better durability properties $(13,25,34)$. In this experiment, the portlandite content has been reduced by the incorporation of silica fume and also AR glass fibers with zirconium content exceeding 16\% were used. The mineralogical study has confirmed that the portlandite is not present in the outer layer of the $2.4 \mathrm{GF}$ in $\mathrm{W}$-series. However, the degradation effects are still significant. This is because the diffusion of sulphate ion from the seawater into the cement paste matrix increases the sulphate concentration of the pore water. When the sulphate concentration increases, the monosulphate aluminate hydrates phase of the cement matrix is transformed back into ettringite. This has resulted in the expansion of the cement paste matrix surrounding the glass fiber and subsequent debonding of the glass fiber from the cement paste matrix (6). The extent of debonding increases with higher concentration of sulphate ion in the pore water. Hence, on prolonged curing in the seawater, the concentration of sulphate ion and the degree of debonding increased with time. The debonding of glass fiber from the cement paste matrix is the primary reason behind the observed reduction in the compressive strength of the GFRC on prolonged exposure to seawater. Thus, it is not viable to apply AR glass fibers as the discrete reinforcement for high strength concrete used in marine environment.

\subsection{Permeability}

The intrinsic permeability of the specimens subjected to different exposure environments is shown in Figure 4 to Figure 6. Based on Figure 4 and Figure 5, the GFRC specimens in both exposure environments (tropical climate and wet and dry cycle) have a lower increasing rate compared to the CTRL specimens. In tropical climate condition, the lowest permeability was observed for $0.6 \mathrm{GF}$ concrete samples at $1.01 \times 10^{-16}$ $\mathrm{m}^{2}$, about $43.6 \%$ lower than the intrinsic air permeability of CTRL which was recorded as $1.79 \times 10^{-16}$ $\mathrm{m}^{2}$. Although the permeability of GRFC increases with the increasing fiber content, the fluctuation of 


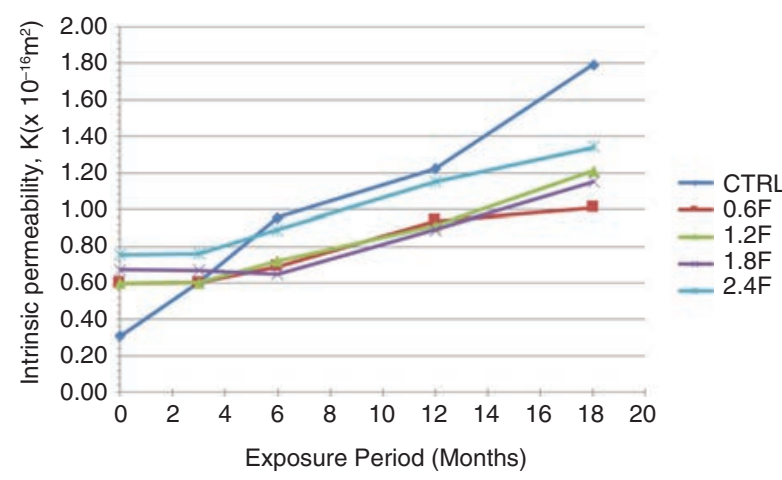

FIGURE 4. Intrinsic permeability of A-series specimens versus the exposure period.

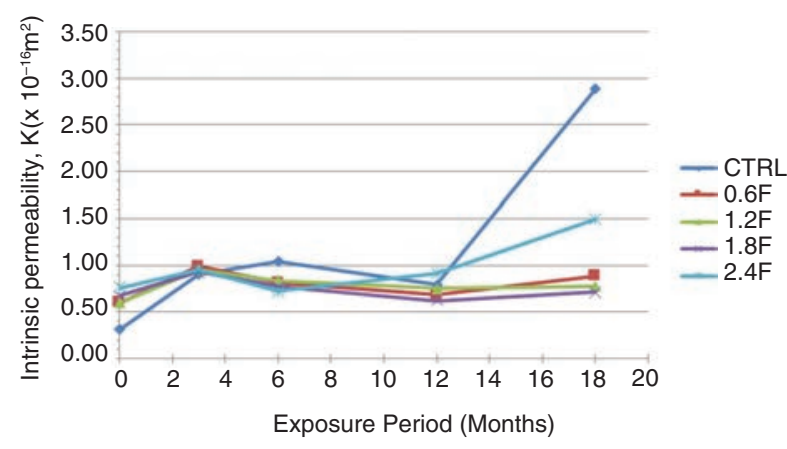

FIGURE 5. Intrinsic permeability of $\mathrm{N}$-series specimens versus the exposure period.

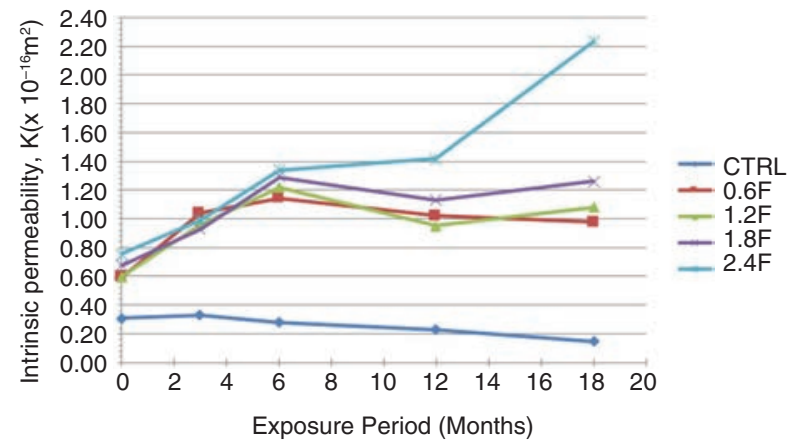

FIGURE 6. Intrinsic permeability of $\mathrm{W}$-series specimens versus exposure period.

temperature in tropical air environment can cause the specimens dimensional instability. The variations in temperature increase the intrinsic air permeability over the exposure durations (6). The inclusion of AR glass fiber in the concrete mix would result in an increased volume of the paste-fiber ITZ in the concrete matrix which in turn resulted in an increase in the intrinsic permeability and porosity of the mix prior to exposure. On prolonged exposure to the tropical air (Environment type A) and cyclic wetting and drying (Environment N) the cement paste of all concrete test samples underwent drying shrinkage which resulted in the formation of drying shrinkage crack on the test sample that led to higher pore continuity. In the presence of the AR fiber within the GFRC samples, the crack bridging effect of the AR fibre reduced the degree of drying shrinkage crack as compared to the control concrete without fibre content. With the reduction in the degree of shrinkage crack, a corresponding reduction in the pore continuity expressed as intrinsic permeability could be achieved for the GFRC over a prolonged tropical air drying exposure. Dimensional instability was further magnified in the specimens subjected to wetting-drying cycles (N-series) in which expansions and shrinkages occurred in a cyclic manner. Figure 5 shows a drastic increase in the intrinsic permeability of the CTRL specimens, from $0.80 \times 10^{-16} \mathrm{~m}^{2}$ to $2.88 \times 10^{-16} \mathrm{~m}^{2}$ when the exposure period was extended from 12 months to 18 months. This was due to the interconnection of micro cracks and continuous pathways formed, allowing nitrogen gas to pass through the concrete specimen easily. However, GFRC with fiber content of 0.6 , 1.2 and $1.8 \%$ did not show any drastic increase in the intrinsic air permeability on prolonged exposure duration to cyclic wetting and drying up to 18 months of exposure duration. These observations highlighted the importance of discontinuous fibers in resisting crack formation and propagation caused by volume change. In addition, the dispersion of micro cracks (35) and bridging up of cracks by the fibers increased the tortuosity of the pathways for the nitrogen gas used in the intrinsic air permeability test. Consequently, the intrinsic air permeability of the GFRC is lower as compared to the CTRL. Banthia \& Bhargava (36) had also confirmed that the FRC exhibits reduced the permeability coefficients under stressed and non-stressed conditions of the cracked concrete.

The permeability of the $2.4 \mathrm{GF}$ also shows an abrupt increase over the period of exposure in Figure 5 and Figure 6. In cyclic exposure (N-series), the intrinsic permeability of $2.4 \mathrm{GF}$ increased from $0.91 \times 10^{-16} \mathrm{~m}^{2}$ to $1.49 \times 10^{-16} \mathrm{~m}^{2}$, whereas in W-series, it increased from $1.42 \times 10^{-16} \mathrm{~m}^{2}$ to $2.23 \times 10^{-16} \mathrm{~m}^{2}$ when the exposure period was extended from 12 months to 18 months. The magnitude was relatively higher in W-series as it was due to the corrosion of the AR glass fibers in seawater coupled with the debonding of fiber from the cement paste matrix resulted by the sulphate expansion of the cement paste matrix. In addition, the porous structure at the surrounding fiber filaments was observed during the SEM examination. This finding is consistent with the argument that the specimens immersed in seawater will exhibit high corrosion rates. Furthermore, it was justified by the rapid reduction in the compressive strength of GFRC specimens and the SEM images (Figure 12).

Nonetheless, the permeability of the CTRL specimen in $\mathrm{W}$-series was decreased on the prolonged exposure to seawater. The reduction in the intrinsic air permeability of the CTRL specimen was associated with salt crystal formation within the capillary pore of the concrete. Discontinuity in the capillary pores caused by the blockage of salt crystals in the pore network resulted in higher resistance to the permeability gas 
$(6,37)$. As the CTRL does not contain any glass fiber reinforcement, there is no debonding of fiber from the cementitious matrix in the control mix (CTRL) due to sulphate expansion. Hence, the exposure of CTRL to seawater exposure (sulphate ion rich solution) did not have a significant effect on air permeability.

Comparing among Figure 4 to Figure 6, the permeability of the GFRC specimens exposed to seawater improved after 3 months. As the exposure period approached 12 months, the values from the $\mathrm{N}$-series specimens reached the lowest levels, followed by those of the A- and W-series. At 18 month, the highest permeability among all the GFRC was obtained by the $2.4 \mathrm{GF}$ in the $\mathrm{W}$-series; the second highest was obtained by the $2.4 \mathrm{GF}$ in the $\mathrm{N}$-series. These results proved that seawater exposure had a significant adverse effect on the GFRC specimens especially those with fiber content. As for test samples subjected to continuous sea water immersion as in the W-series, the effect of drying shrinkage crack was eliminated. Hence, the permeability and compressive strength results are relatively consistent.

\subsection{Chloride Diffusion}

The chloride content (percentage by mass of cement) is reported in Table 2. After the immersion in seawater for 18 months, the water soluble chloride content of all the GFRC at the sampling interval of
20-30 mm was still observed to be lower than the maximum allowable content of $0.2 \%$ as prescribed in the ACI Comittee 222R-01 (38). The sampling depth interval of $20-30 \mathrm{~mm}$ was considered as it is equivalent to the typical depth of concrete cover provided for reinforced concrete structural element as prescribed in the BS EN 1992-1-1:2004+A1:2014 (39). Figure 7 shows the chloride concentrations of specimens in $\mathrm{W}$-series up to $20 \mathrm{~mm}$ depth level. The rationale to discard the data in depth levels 20-30 $\mathrm{mm}$ and $30-40 \mathrm{~mm}$ from displaying in the Figure is to avoid the misinterpretation of the test results, since the chloride concentrations at those levels were below the threshold limit of $0.2 \%$.

As referred to Table 2, the inclusion of AR glass fiber at fiber content of $0.6 \%$ up to $2.4 \%$ had resulted in a significant increase in the chloride content of the GFRC produced especially for the sampling depth interval of $10-20 \mathrm{~mm}$ at prolonged immersion in seawater (W-Series) as compared to the control concrete (CTRL). Besides that, it was observed that chloride diffusion is a time-dependent process. This is indicated by the increasing concentration of chloride in all the concrete mixes on prolonged seawater immersion duration from 3 months up to 18 months.

The results suggest that the chloride diffusion into the first layer $(10-20 \mathrm{~mm})$ was increased with the increasing fiber content. This trend is in line with the intrinsic air permeability data, suggesting that

TABLE 2. Chloride content (percentage by mass of cement) of all specimens.

\begin{tabular}{|c|c|c|c|c|c|c|c|c|c|}
\hline \multirow{3}{*}{ Specimen } & \multirow{3}{*}{$\begin{array}{c}\text { Period of Exposure } \\
\text { (months) Exposure } \\
\text { Environment } \\
\text { Depths }\end{array}$} & \multicolumn{8}{|c|}{ Chloride Concentration (Percentage by mass of cement) } \\
\hline & & \multicolumn{2}{|c|}{3} & \multicolumn{2}{|c|}{6} & \multicolumn{2}{|c|}{12} & \multicolumn{2}{|c|}{18} \\
\hline & & $\mathbf{N}$ & W & $\mathbf{N}$ & W & $\mathbf{N}$ & W & $\mathbf{N}$ & $\mathbf{W}$ \\
\hline \multirow{4}{*}{ CTRL } & $0-10 \mathrm{~mm}$ & 0.24 & 0.39 & 0.45 & 0.50 & 0.66 & 0.80 & 0.82 & 1.22 \\
\hline & $10-20 \mathrm{~mm}$ & 0.04 & 0.04 & 0.04 & 0.08 & 0.08 & 0.12 & 0.08 & 0.16 \\
\hline & $20-30 \mathrm{~mm}$ & 0.00 & 0.00 & 0.00 & 0.00 & 0.00 & 0.00 & 0.00 & 0.08 \\
\hline & $30-40 \mathrm{~mm}$ & 0.00 & 0.00 & 0.00 & 0.00 & 0.00 & 0.00 & 0.00 & 0.00 \\
\hline \multirow{4}{*}{$0.6 \mathrm{GF}$} & $0-10 \mathrm{~mm}$ & 0.24 & 0.43 & 0.50 & 0.59 & 0.71 & 0.98 & 0.98 & 1.10 \\
\hline & $10-20 \mathrm{~mm}$ & 0.04 & 0.12 & 0.08 & 0.16 & 0.08 & 0.20 & 0.08 & 0.31 \\
\hline & $20-30 \mathrm{~mm}$ & 0.00 & 0.00 & 0.00 & 0.00 & 0.00 & 0.04 & 0.04 & 0.08 \\
\hline & $30-40 \mathrm{~mm}$ & 0.00 & 0.00 & 0.00 & 0.00 & 0.00 & 0.00 & 0.00 & 0.00 \\
\hline \multirow{4}{*}{$1.2 \mathrm{GF}$} & $0-10 \mathrm{~mm}$ & 0.27 & 0.47 & 0.43 & 0.55 & 0.84 & 0.98 & 1.02 & 1.14 \\
\hline & $10-20 \mathrm{~mm}$ & 0.04 & 0.08 & 0.08 & 0.16 & 0.16 & 0.24 & 0.16 & 0.39 \\
\hline & $20-30 \mathrm{~mm}$ & 0.00 & 0.00 & 0.00 & 0.00 & 0.00 & 0.04 & 0.04 & 0.12 \\
\hline & $30-40 \mathrm{~mm}$ & 0.00 & 0.00 & 0.00 & 0.00 & 0.00 & 0.00 & 0.00 & 0.04 \\
\hline \multirow{4}{*}{$1.8 \mathrm{GF}$} & $0-10 \mathrm{~mm}$ & 0.27 & 0.43 & 0.43 & 0.59 & 0.90 & 1.18 & 1.18 & 1.24 \\
\hline & $10-20 \mathrm{~mm}$ & 0.04 & 0.08 & 0.04 & 0.20 & 0.20 & 0.24 & 0.24 & 0.44 \\
\hline & $20-30 \mathrm{~mm}$ & 0.00 & 0.00 & 0.00 & 0.00 & 0.00 & 0.04 & 0.08 & 0.16 \\
\hline & $30-40 \mathrm{~mm}$ & 0.00 & 0.00 & 0.00 & 0.00 & 0.00 & 0.00 & 0.00 & 0.04 \\
\hline \multirow{4}{*}{$2.4 \mathrm{GF}$} & $0-10 \mathrm{~mm}$ & 0.31 & 0.41 & 0.43 & 0.62 & 0.94 & 1.29 & 1.22 & 1. 34 \\
\hline & $10-20 \mathrm{~mm}$ & 0.04 & 0.08 & 0.04 & 0.24 & 0.26 & 0.28 & 0.32 & 0.48 \\
\hline & $20-30 \mathrm{~mm}$ & 0.00 & 0.00 & 0.00 & 0.00 & 0.04 & 0.04 & 0.08 & 0.20 \\
\hline & $30-40 \mathrm{~mm}$ & 0.00 & 0.00 & 0.00 & 0.00 & 0.00 & 0.04 & 0.00 & 0.08 \\
\hline
\end{tabular}


the permeability of the concrete mix is the governing factor which influences the rate of chloride diffusivity. At the duration of 6 months, comparing between the first layer of specimens in W-series, the chloride concentrations obtained by the GFRC specimens were similar to the control concrete CTRL. Except for the second layer $(10-20 \mathrm{~mm})$, the chloride content of the $0.6 \mathrm{GF}$ and $2.4 \mathrm{GF}$ became double and triple of the CTRL at $0.16 \%$ and $0.24 \%$, respectively. It was observed that the chloride content of the specimens in $\mathrm{W}$-series was higher than those in $\mathrm{N}$-series. This is due to the nature of exposure conditions, whereby specimens in $\mathrm{W}$-series have longer exposure period of exposure to the chloride source. However, specimens in $\mathrm{N}$-series have only 4 days of exposure to seawater in one cycle.

\subsection{X-Ray Diffraction}

The XRD patterns of the CTRL and the $2.4 \mathrm{GF}$ immersed in seawater for 18 months are shown in Figure 8 and Figure 9. The results confirmed the

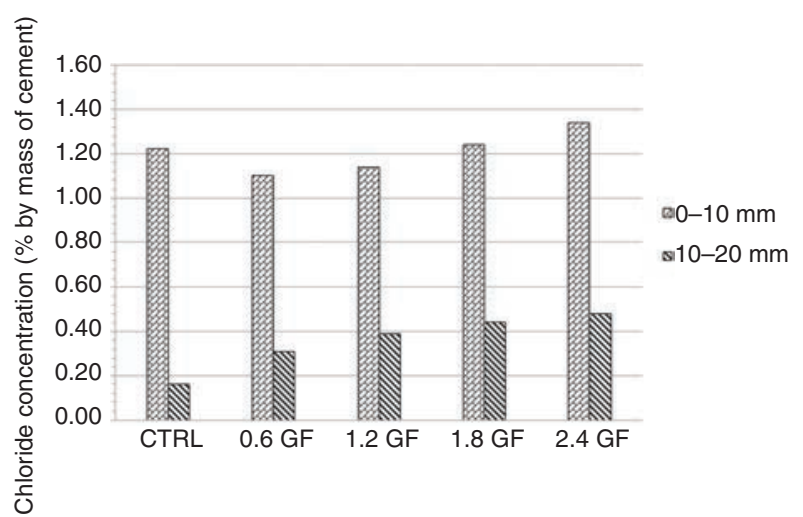

FIGURE 7. Chloride concentrations in W-series after 18 months of exposure occurrence of sulphate attacks from the seawater. Gypsum, and sepiolite which are the products of sulphate attacks were observed to be present in the samples subjected to prolonged seawater exposure (1-3). In addition, $\mathrm{Ca}(\mathrm{OH})_{2}$ was not detected at the outer layer of the specimens which could have been consumed by the silica fume present in the concrete mix via pozzolanic reactions.

\subsection{SEM Examination}

Figure 10 to Figure 12 show the results of the SEM examinations, whereas Tables 3 present the results of the EDX analysis. Figure 10 shows the brittleness of the AR glass fiber. The densification in the space between the fiber strands and the fiber/matrix interface caused the fibers to break into shorter fiber fragments. This creates a weak layer in the binder matrix while eliminating the reinforcing action of the glass fiber. The bond strength developed by densification exceeded the bending strength of the fine and brittle fibers, hence, resulting in the premature fracture of the glass fibers. The internal stresses developed due to the fact that the autogeneous and drying shrinkage of the cement paste matrix easily exceeded the critical flexural strength values of the fine glass fiber filament.

In addition to the premature fracture of the fibers, the increases in size and number of cracks in the $2.4 \mathrm{GF}$ specimens exposed to tropical climate for 18 months were also responsible for the strength reduction. The micro cracks developed will eventually combine to form macro cracks. Large air voids were also found in the surrounding area of the fiber bundle. This observation indicates that the incorporation of multiple-strand AR glass fiber imposes the risk of trapping air voids within the cement paste matrix of the concrete mix.

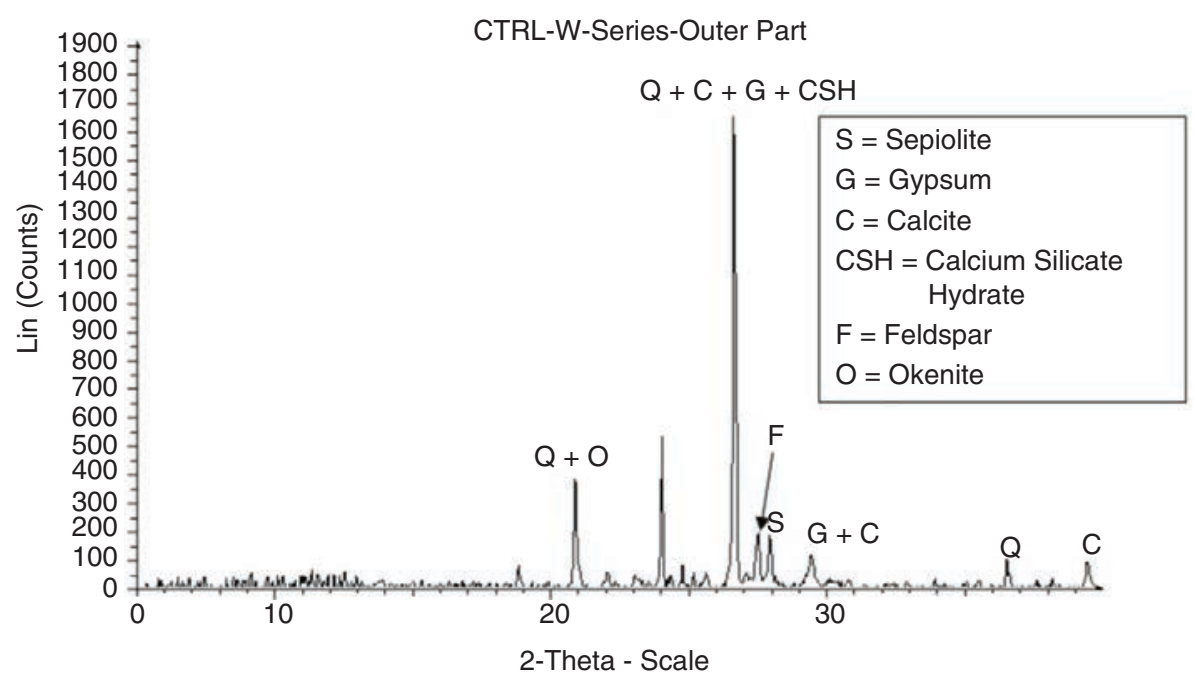

FIGURE 8. XRD pattern of the outer part of the CTRL in the W-series for 18 months. 
Alkali-resistant glass fiber reinforced high strength concrete in simulated aggressive environment $\bullet 9$

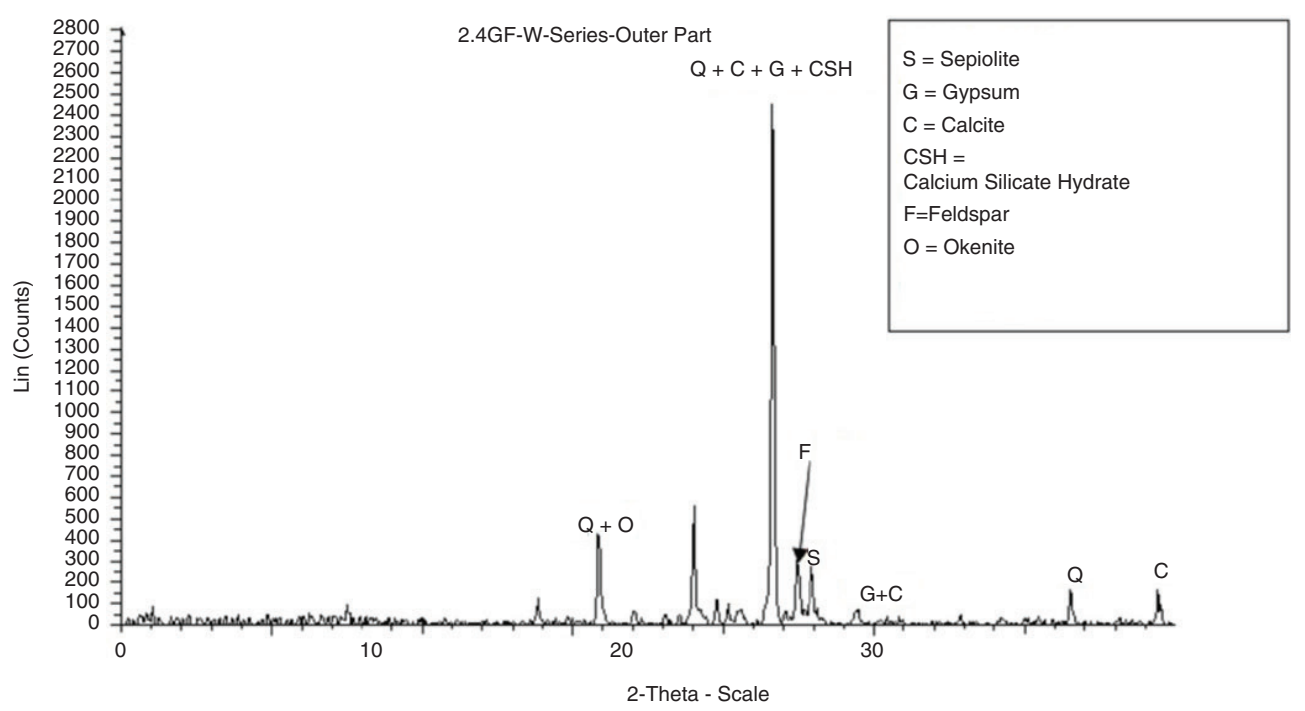

FIGURE 9. XRD pattern of the outer part of the $2.4 \mathrm{GF}$ in the W-series for 18 months.

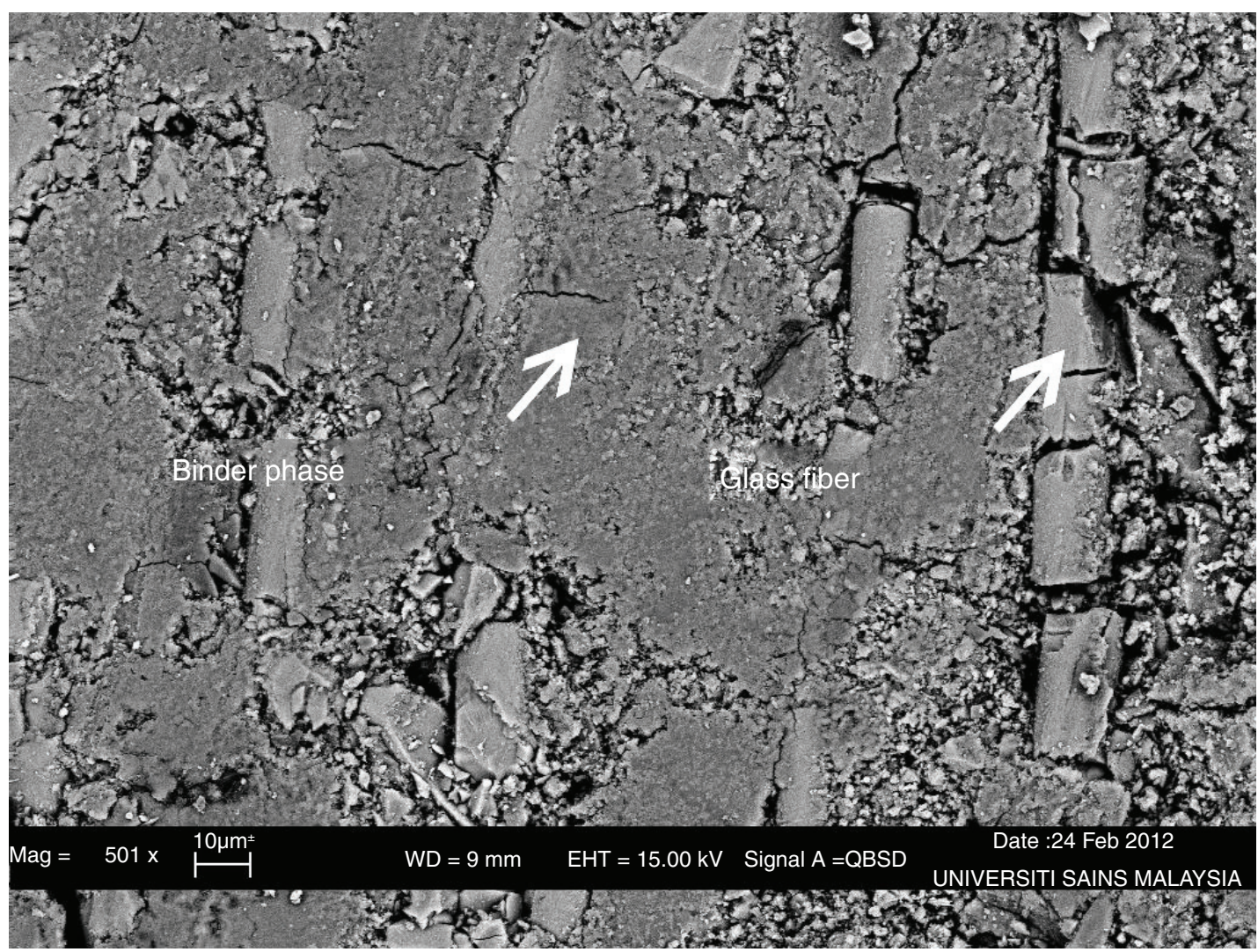

Figure 10. SEM image (501× magnification) of the $2.4 \mathrm{GF}$ in the A-series at 18 months.

There was a gap observed to be present between the glass fiber and the cement paste matrix most likely due to the presence of a thin film of mixing water on the surface of the fiber during the mixing of the GFRC mix. The gap exhibits uniformity in size and shape and is connected by a macro crack. The gap present may hinder the friction between the fiber and the matrix during a fiber pull-out. The particles packed in the surrounding area of the gap appeared loose, and poor bonding was observed. These findings justify the lower strength of $2.4 \mathrm{GF}$ in the long term as compared with all other A-series specimens.

Figure 11 shows that the fiber remained in good condition, similar to the A-series, and that no 


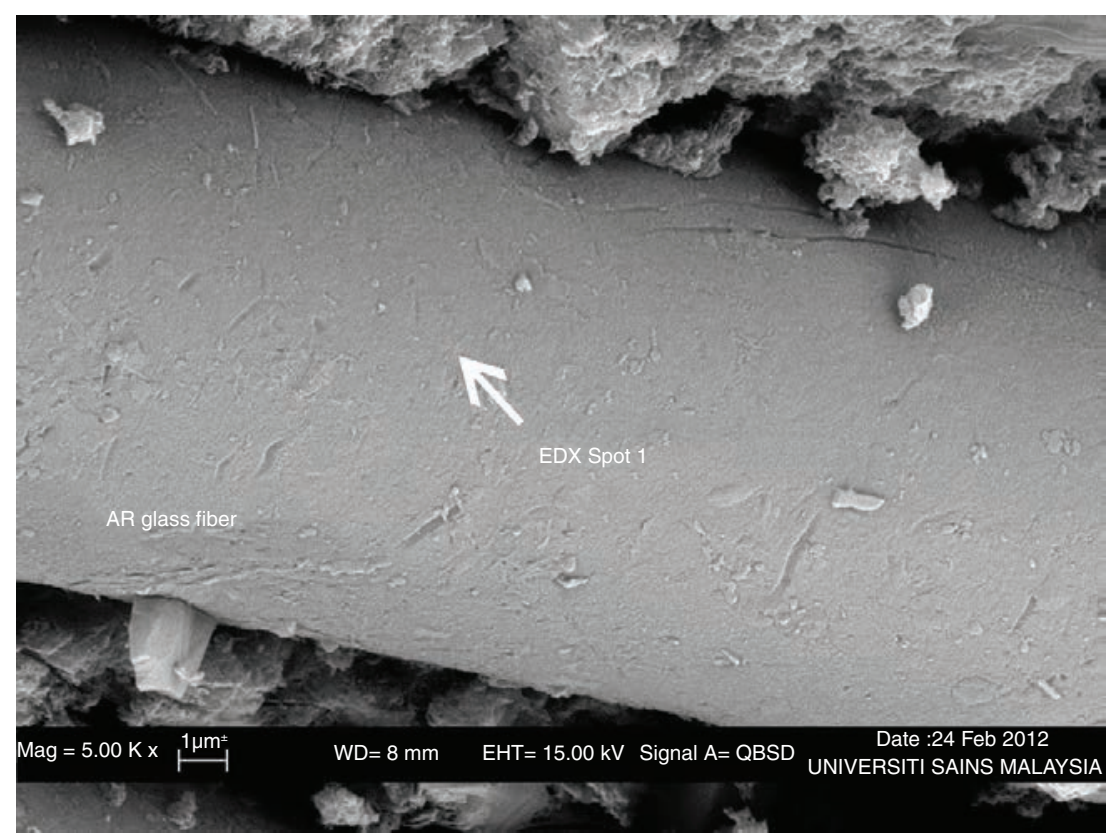

FIGURE 11. SEM image $(5000 \times$ magnification $)$ of the $2.4 \mathrm{GF}$ in the $\mathrm{N}$-series at 18 months

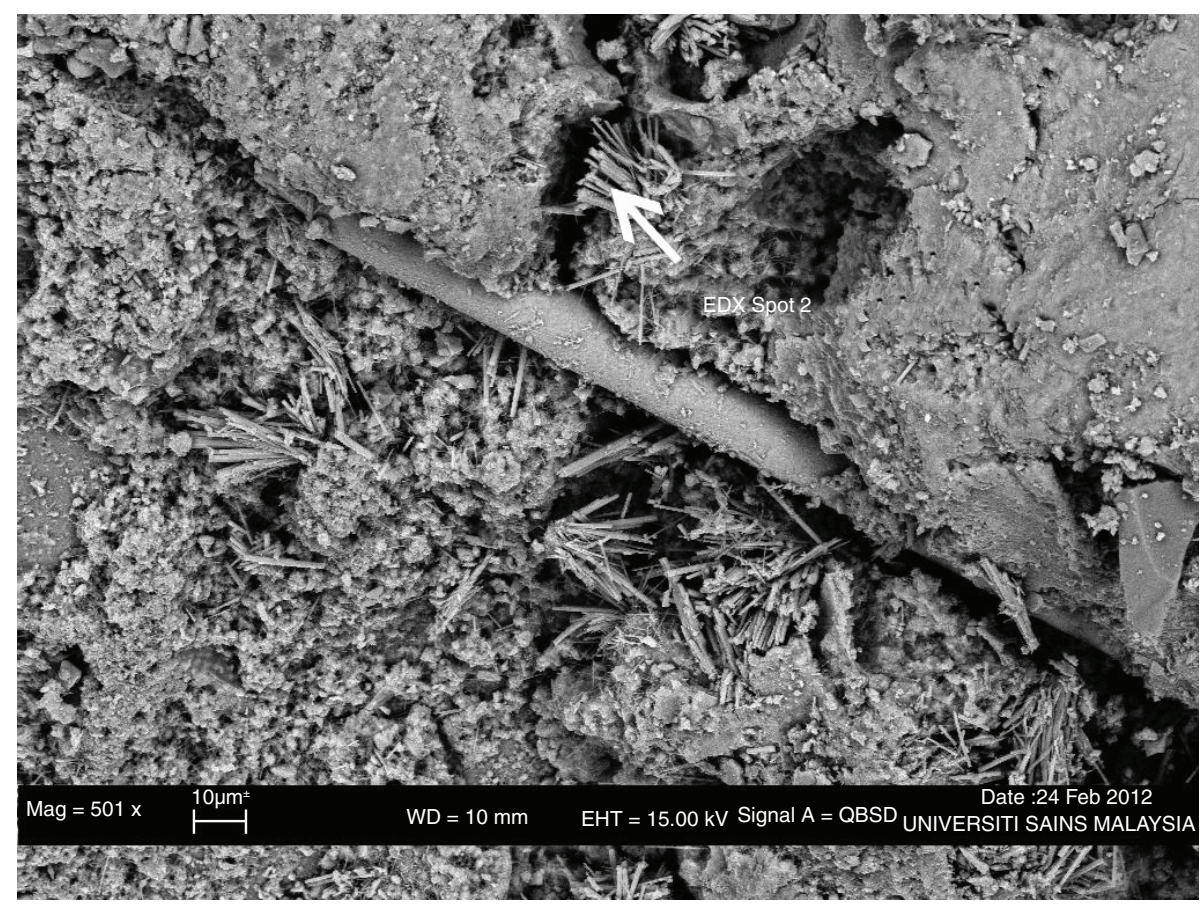

FIGURE 12. SEM image $(501 \times$ magnification $)$ of the $2.4 \mathrm{GF}$ in the $\mathrm{W}$-series at 18 months.

deterioration was observed. The EDX analysis of Spot 1 revealed that the zirconium content decreased to $10.86 \%$; however, the zirconium content should exceed $16 \%$ to maintain superior durability (14). The result of the EDX analysis is presented in Table 3.
The $\mathrm{OH}^{-}$ions from the exposure environment tend to attack the Si-O-Si structural network of the glass, hence, weakening the mechanical properties of the glass fiber. The AR glass fiber coated with $\mathrm{ZrO}_{2}$ is less susceptible to $\mathrm{OH}^{-}$ion attack considering that 
$\mathrm{Zr}-\mathrm{O}$ bonds are less reactive to $\mathrm{OH}^{-}$ions, thereby slowing down the degradation $(34,36)$. Nonetheless, the zirconium content was decreased by chemical corrosion to a level below the pessimum. Hence, the deterioration of the fiber is expected to occur on prolonged exposure to $\mathrm{OH}^{-}$ion rich solutions such as the seawater.

Figure 12 shows the microstructure of the $2.4 \mathrm{GF}$ in the $\mathrm{W}$-series. A porous matrix was found in the surrounding area of the fiber strand. Needle-like crystals were observed to be formed within the cement matrix surrounding the glass fiber. The EDX Spot 2 analysis was performed on the needle like crystals to identify the chemical compositions and the results are presented in Table 4. The results of EDX analysis indicate that the needle-like crystals are ettringite

TABLE 3. Elements at EDX Spot 1.

\begin{tabular}{lc}
\hline Element & Weight (\%) \\
\hline O K & 53.54 \\
Na K & 6.7 \\
Al K & 0.47 \\
Si K & 22.36 \\
K K & 1.33 \\
Ca K & 2.67 \\
Ti K & 2.07 \\
Zr L & $\mathbf{1 0 . 8 6}$ \\
Total & 100 \\
\hline
\end{tabular}

$\left(3 \mathrm{CaO} \cdot \mathrm{Al}_{2} \mathrm{O}_{3} \cdot 3 \mathrm{CaSO}_{4} \cdot 32 \mathrm{H}_{2} \mathrm{O}\right)$. The formation of ettringite is due to the decomposition of the monosulphate aluminate hydrate crystals when the concentration of sulphate ions of the pore water is high due to the ingress of sulphate ions from seawater into the concrete. The formation of ettringite within the cement paste matrix surrounding the glass fiber actually resulted in an expansion of the cement paste matrix as the volume of ettringite mineral is two and a half times the volume of monosulphate aluminate hydrate minerals (30). The expansion of the ettringite mineral and decomposition of monosulphate aluminate hydrate had both contributed to the increased porosity of the fiber/cement paste interface zone and also the debonding of the fiber from the cement paste matrix as can be observed in micrographs in Figure 19. These actions have led to the elimination of the reinforcing capability of the glass fiber, hence, resulting in a significantly lower mechanical strength of the GFRC as compared to control concrete (CTRL) when the specimens were subjected to seawater exposure. Moreover, under the same exposure condition, the highly porous fiber/ cement paste matrix interface had created channels of continuous flow path, hence, increasing the air permeability of all the GFRC as compared to the control concrete as observed earlier in Figure 6.

Figure 13 indicates that the corroded surface (circled in red) of the glass fiber was due to the reaction with $\mathrm{OH}^{-}$ions. The EDX analysis at Spot 3 (result in Table 5) shows that the zirconium content

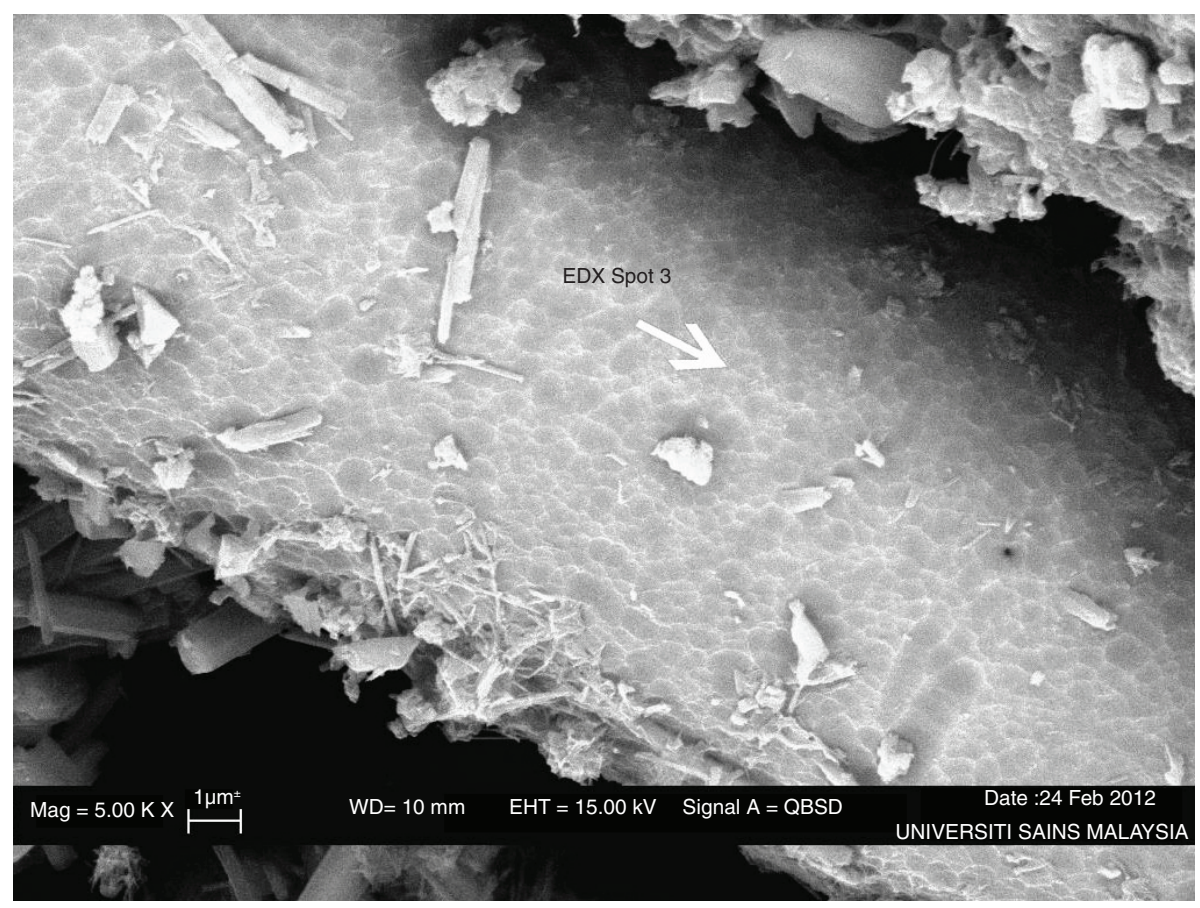

FIGURE 13. SEM image $(5000 \times$ magnification) of the $2.4 \mathrm{GF}$ in the W-series at 18 months. 
TABLE 4. Elements at EDX Spot 2.

\begin{tabular}{lc}
\hline Element & Weight (\%) \\
\hline C K & 5.87 \\
O K & 60.45 \\
Al K & 3.22 \\
Si K & 8.65 \\
S K & 6.48 \\
Ca K & 15.33 \\
Total & 100 \\
\hline
\end{tabular}

TABle 5. Elements at EDX Spot 3.

\begin{tabular}{lc}
\hline Element & Weight (\%) \\
\hline O K & 47.46 \\
Na K & 6.16 \\
Al K & 0.5 \\
Si K & 25.06 \\
K K & 3.74 \\
Ca K & 4.45 \\
Ti K & 2.67 \\
Zr L & $\mathbf{9 . 9 6}$ \\
Total & 100 \\
\hline
\end{tabular}

dropped to $9.96 \%$. The microstructures of the matrix and the glass fibers were severely damaged by the seawater attack. Consequently, the highest strength loss and the increase in the intrinsic air permeability were observed for the concrete mixes with relatively high fiber content namely $1.8 \mathrm{GF}$ and 2.4 GF subjected to seawater exposure environment, as indicated in Figure 3 and Figure 6. Results of micro structural studies show that despite being a durable engineered fiber, the AR glass fiber may not be suitable for use as discrete fiber reinforcements in high strength concrete intended for the fabrication of marine structures.

\section{CONCLUSIONS}

An overview of the development, properties of GFRC has been outlined. Based on the experimental studies, several conclusions can be drawn:

- The addition of glass fibers into high strength concrete showed no positive effects in terms of the compressive strength after long-term exposure to the simulated environment attacks. The drop in the compressive strength of the GFRCs after 12 months' exposure was caused by the premature fracture of fiber filaments.

- The localized reinforcing effects from the glass fibers prevent a drastic increase in the permeability and strengths of the GFRC specimens subjected to 18 months of exposure to the tropical climate and cyclic wetting and drying. Nonetheless, the fiber content should be maintained at $1.2 \%$ and below for optimum durability performance of GFRC.

- The GFRC with the highest fiber content (2.4 GF) was observed in terms of its strength loss in the A-, N- and W- series for 18 months. An abrupt increase in its intrinsic permeability was observed in $\mathrm{N}$ - and $\mathrm{W}$-series exposure conditions and $\mathrm{W}$-series is the most substantial. These suggest that AR glass fiber is not viable as discrete fiber reinforcements for high strength concrete structures which are exposed to marine environment. The matrix surrounding the fiber of the $2.4 \mathrm{GF}$ in the $\mathrm{W}$-series was porous, and the fiber was corroded. The zirconium content was observed to drop below $16 \%$.

- The expansion of the ettringite mineral and decomposition of monosulphate aluminate hydrate had both contributed to the increased porosity of the fiber/cement paste interface zone and also the debonding of the fiber from the cement paste matrix eliminating the reinforcing effects of the glass fiber. Moreover, the corrosion of glass fiber by the $\mathrm{OH}^{-}$contributes further to the weakening of the mechanical performance of GFRC upon being subjected to aggressive exposure environment.

- The chloride diffusivity of GFRC is strongly governed by its intrinsic air permeability. Generally, it was observed that both the chloride diffusivity and air permeability of GFRC increases with the increase in its fiber content. The recommended fiber content of AR glass fiber reinforcement to ensure low chloride diffusivity and air permeability is in the range of $0.6-$ $1.2 \%$ by volume of binder.

\section{ACKNOWLEDGMENTS}

The authors would like to express their sincere gratitude to the Universiti Sains Malaysia and the Ministry of Higher Education for providing the Fundamental Research Grant Scheme.

\section{NOTATION}

The following symbols are used in this paper:

$\mathrm{K}=$ is intrinsic permeability, $\mathrm{m}^{2}$;

$\mathrm{P}_{1}=$ is absolute applied pressure bars [pressure used + atmosphere pressure] usually 2 bars;

$\mathrm{P}_{2}=$ is pressure at which the flow rate is measured [atmosphere pressure], usually 1 bar;

$\mathrm{A}=$ is cross section areas of specimen, $\mathrm{m}^{2}$;

$\mathrm{L}=$ is thickness of specimen, $\mathrm{m}$;

$\mathrm{V}=$ is the flow rate, $\mathrm{cm}^{3} / \mathrm{sec}$; 
$m^{\text {sat }}=$ is the mass of the saturated specimen;

$m^{\text {dried }}=$ is the mass of the oven-dried specimen;

$m^{\text {water }}=$ is the mass of the specimen in water;

$V_{5}=$ is the volume of $0.1 \mathrm{M}$ silver nitrate solution added, $\mathrm{mL}$; $\mathrm{mL}$;

$V_{6}=$ is the volume of thiocyanate solution used,

$M_{\mathrm{c}}=$ is the mass of sample used, $\mathrm{g}$;

$M=$ is the molarity of the thiocyanate solution, $\mathrm{mol} / \mathrm{L}$; and

$C_{1}=$ is the cement content of the sample used, $\%$.

\section{REFERENCES}

1. Neville, A. (2004). The confused world of sulfate attack on concrete. Cem. Concr. Res. 34 [8], 1275-1296. https://doi. org/10.1016/j.cemconres.2004.04.004

2. Małolepszy, J.; Grabowska, E. (2015). Sulphate Attack Resistance of Cement with Zeolite Additive. Procedia Eng. 108, 170-176. https://doi.org/10.1016/j.proeng.2015.06.133

3. Muthusamy, K.; Kamaruzzaman, N.W.; Zubir, M.A.; Hussin, M.W.; Sam, A.R.M.; Budiea, A. (2015). Long Term Investigation on Sulphate Resistance of Concrete Containing Laterite Aggregate. Procedia Eng. 125, 811817. https://doi.org/10.1016/j.proeng.2015.11.145

4. Piasta, W.; Marczewska, J.; Jaworska, M. (2015). Durability of Air Entrained Cement Mortars Under Combined Sulphate and Freeze-thaw Attack. Procedia Eng. 108, 55-62. https://doi.org/10.1016/j.proeng.2015.06.119

5. Soroushian, P.; Elzafraney, M. (2004). Damage effects on concrete performance and microstructure. Cem. Concr. Compos. 26 [7], 853-859. https://doi.org/10.1016/j. cemconcomp.2003.05.001

6. Ramli, M.; Kwan, W.H.; Abas, N.F.(2013). Application of noncorrosive barchip fibres for high strength concrete enhancements in aggressive environments. Composites Part B 53, 134-144. https://doi.org/10.1016/j.compositesb.2013.04.012

7. Brandt, A. M. (2008). Fibre reinforced cement-based (FRC) composites after over 40 years of development in building and civil engineering. Compos. Struct. 86 [1-3], 3-9. https://doi.org/10.1016/j.compstruct.2008.03.006

8. Etse, G.; Caggiano, A.; Vrech, S. (2012). Multiscale failure analysis of fiber reinforced concrete based on a discrete crack model. Int. J. Fract. 178 [1], 131-146. https://doi. org/10.1007/s10704-012-9733-z

9. Kang, J.; Kim, K.; Lim, Y.M.; Bolander, J. E. (2014). Modeling of fiber-reinforced cement composites: Discrete representation of fiber pullout. Intern Int. J. Solids Struct. 51 [10], 1970-1979. https://doi.org/10.1016/j. ijsolstr.2014.02.006

10. Lee, S.C.; Cho, J.Y; Vecchio, F.J. (2013). Simplified diverse embedment model for steel fiber-reinforced concrete elements in tension. ACI Mater. J. 110 [4], 403-412. https:// doi.org/10.14359/51685787.

11. Mallick, P. (2008). Fibre-Reinforced Composites: Materials Manufacturing and Design. Boca Raton: Taylor \& Francis Group, Abingdon, (2008)

12. Axinte, E. (2011). Glasses as engineering materials: A review. Mater. Des. 32 [4], 1717-1732. https://doi. org/10.1016/j.matdes.2010.11.057

13. ASTM C1666/C1666M - 08 Standard Specification for Alkali Resistant (AR) Glass Fiber for GFRC and Fiber Reinforced Concrete and Cement.

14. Gilbert, G.T. (2004). GFRC - 30 Years Of High Fiber Cement Composite Applications Worldwide. Special Publication 224 [1-20]. Retrieved from https://www. concrete.org/publications/internationalconcreteabstractsportal.aspx?m=details \&ID $=13404$

15. Lipatov, Y.V.; Gutnikov, S.I.; Manylov, M.S.; Zhukovskaya, E.S.; Lazoryak, B.I. (2015). High alkali-resistant basalt fiber for reinforcing concrete. Mater. Des. 73 [60-66]. https://doi.org/10.1016/j.matdes.2015.02.022
16. Köksal, F.; Altun, F.; Yiğit, İ.; Şahin, Y. (2008). Combined effect of silica fume and steel fiber on the mechanical properties of high strength concretes. Constr. Build. Mater. 22 [8], 1874 1880. https://doi.org/10.1016/j.conbuildmat.2007.04.017

17. Goh, K.L.; Meakin, J.R.; Hukins, D.W.L. (2010). Influence of fibre taper on the interfacial shear stress in fibre-reinforced composite materials during elastic stress transfer. Compos. Interfaces 17 [1], 74-80. https://doi.org/10.1163/0 92764409X12580201111665

18. Kwan, W.H.; Ramli, M.; Cheah, C.B. (2014). Flexural strength and impact resistance study of fibre reinforced concrete in simulated aggressive environment. Constr. Build. Mater. 63, 62-71. https://doi.org/10.1016/j.conbuildmat.2014.04.004

19. Liang, J.Z. (2012). Predictions of Young's modulus of short inorganic fiber reinforced polymer composites. Composites Part B 43 [4], 1763-1766. https://doi.org/10.1016/j. compositesb.2012.01.010

20. Mo, K.H.; Yap, S.P.; Alengaram, U.J.; Jumaat, M.Z.; Bu, C.H. (2014). Impact resistance of hybrid fibre-reinforced oil palm shell concrete. Constr. Build. Mater. 50, 499-507. https://doi.org/10.1016/j.conbuildmat.2013.10.016

21. Mohonee, V.K.; Goh, K.L. (2016). Effects of fibre-fibre interaction on stress uptake in discontinuous fibre reinforced composites. Composites Part B 86, 221-228. https:// doi.org/10.1016/j.compositesb.2015.10.015

22. Yu, R.; van Beers,L.; Spiesz, P.; Brouwers, H.J.H. (2016). Impact resistance of a sustainable Ultra-High Performance Fibre Reinforced Concrete (UHPFRC) under pendulum impact loadings. Constr. Build. Mater. 107, 203-215. https://doi.org/10.1016/j.conbuildmat.2015.12.157

23. Barluenga, G.; Hernández-Olivares, F. (2007). Cracking control of concretes modified with short AR-glass fibers at early age. Experimental results on standard concrete and SCC. Cem. Concr. Res. 37 [12], 1624-1638. https://doi. org/10.1016/j.cemconres.2007.08.019

24. Messan, A.; Ienny, P.; Nectoux, D. (2011). Free and restrained early-age shrinkage of mortar: Influence of glass fiber, cellulose ether and EVA (ethylene-vinyl acetate). Cem. Concr. Compos. 33 [3], 402-410. https://doi. org/10.1016/j.cemconcomp.2010.10.019

25. Nourredine, A. (2011). Influence of curing conditions on durability of alkali-resistant glass fibres in cement matrix. Bull. Mater. Sci. 34 [4], 775. https://doi.org/10.1007/ s12034-011-0194-1

26. Purnell, P.; Beddows, J. (2005). Durability and simulated ageing of new matrix glass fibre reinforced concrete. Cem. Concr. Compos. 27 [9], 875-884. https://doi.org/10.1016/j. cemconcomp.2005.04.002

27. Butler, M.; Mechtcherine, V.; Hempel, S. (2009). Experimental investigations on the durability of fibrematrix interfaces in textile-reinforced concrete, Cem. Concr. Compos. 31 [4], 221-231. https://doi.org/10.1016/j. cemconcomp.2009.02.005

28. Ramli, M.; Kwan, W. H. (2010). Influences of Short Discrete Fibers in High Strength Concrete with Very Coarse Sand. Am. J. Applied Sci. 7 [12], 1572-1578. https:// doi.org/10.3844/ajassp.2010.1572.1578

29. BS EN 12390-3. (2009). "Testing Hardened Concrete: Compressive Strength of Test Specimens."

30. Cabrera, J. G.; Lynsdale, C. J. (1988). A new gas permeameter for measuring the permeability of mortar and concrete. Mag. Concr. Res. 40 [144], 177-182. https://doi. org/10.1680/macr.1988.40.144.177

31. BS 1881-124. (1992). "Testing Concrete: Method for Analysis of Hardened Concrete."

32. Lothenbach, B.; Scrivener, K.; Hooton, R. D. (2011). Supplementary cementitious materials. Cem. Concr. Res. 41 [12], 1244-1256. https://doi.org/10.1016/j.cemconres. 2010.12.001

33. Yilmaz, V.; Glasser, F. (1991). "Reaction of AlkaliResistant Glass Fibres with Cement. Part 1." Review, Assessment, and Microscopy." Glass Technol. 32, 91-98.

34. Purnell, P.; Short, N.; Page, C.; Majumdar, A. (2000). Microstructural observations in new matrix glass fibre reinforced cement. Cem. Concr. Res.30 [11], 1747-1753. https://doi.org/10.1016/S0008-8846(00)00407-5 
$14 \cdot$ W. H. Kwan et al.

35. Błaszczyński, T.; Przybylska-Fałek, M. (2015). Steel Fibre Reinforced Concrete as a Structural Material. Procedia Eng. 122, 282-289. https://doi.org/10.1016/j.proeng.2015.10.037

36. Banthia, A.; Bhargava, N. (2007). Permeability of Stressed Concrete and Role of Fiber Reinforcement. ACI Mater. J.104 [1]. https://doi.org/10.14359/18497

37. Ganjian, E.; Pouya, H. S. (2009). The effect of Persian Gulf tidal zone exposure on durability of mixes containing silica fume and blast furnace slag. Constr. Build. Mater. 23 [2], 644-652. https://doi.org/10.1016/j. conbuildmat.2008.02.009

38. ACI Committee 222R-01. (2001). "Protection of metals in concrete against corrosion." American Concrete Institute.

39. BS EN 1992-1-1:2004+A1:2014. "Eurocode 2: Design of concrete structures. General rules and rules for buildings" 